\title{
Long-term efficacy and safety of omalizumab in conventional treatment-resistant vernal keratoconjunctivitis: case reports and literature review
}

\author{
Sara Manti ${ }^{1}$, Giuseppe Fabio Parisi ${ }^{2}$, Maria Papale ${ }^{1}$, Gian Luigi Marseglia ${ }^{3}$, Amelia \\ Licari $^{3}$, and salvatore leonardi ${ }^{1}$ \\ ${ }^{1}$ University of Catania School of Medicine \\ ${ }^{2}$ University of Catania \\ ${ }^{3}$ Fondazione IRCCS Policlinico San Matteo
}

July 30, 2020

\begin{abstract}
Vernal keratoconjunctivitis (VKC) is a severe chronic ocular disease characterized by recurring acute and/or chronic cornealconjunctival inflammation leading to visual sequelae. Since no therapy is universally effective at treating VKC, novel treatments are currently under investigation, such as anti-immunoglobulin (Ig)E [1]. Omalizumab, a recombinant monoclonal antibody ( $\mathrm{mAb}$ ) binding to the Fce portion of the immunoglobulin ( $\mathrm{Ig}) \mathrm{E}$, has been licensed by the Food and Drug Administration (FDA) and European Medicines Agency (EMA) as an add-on therapy for the treatment of severe not controlled allergic asthma both in adults and children (age [?] six years), [2-4] as well as in severe chronic idiopathic urticaria, and even as off-label use in other diseases $[5,6]$. Although the clinical efficacy and safety of omalizumab have already been extensively investigated in the treatment of other IgE-mediated diseases [7, 8], very few literature data support the use of omalizumab in VKC [9-14]. In the present study, we report our clinical experience with omalizumab to treat severe VKC unresponsive to standard therapy in two children. An updated overview of the current literature is also provided.
\end{abstract}

\section{Hosted file}

Manuscript.doc available at https://authorea.com/users/340024/articles/473193-longterm-efficacy-and-safety-of-omalizumab-in-conventional-treatment-resistant-vernalkeratoconjunctivitis-case-reports-and-literature-review 

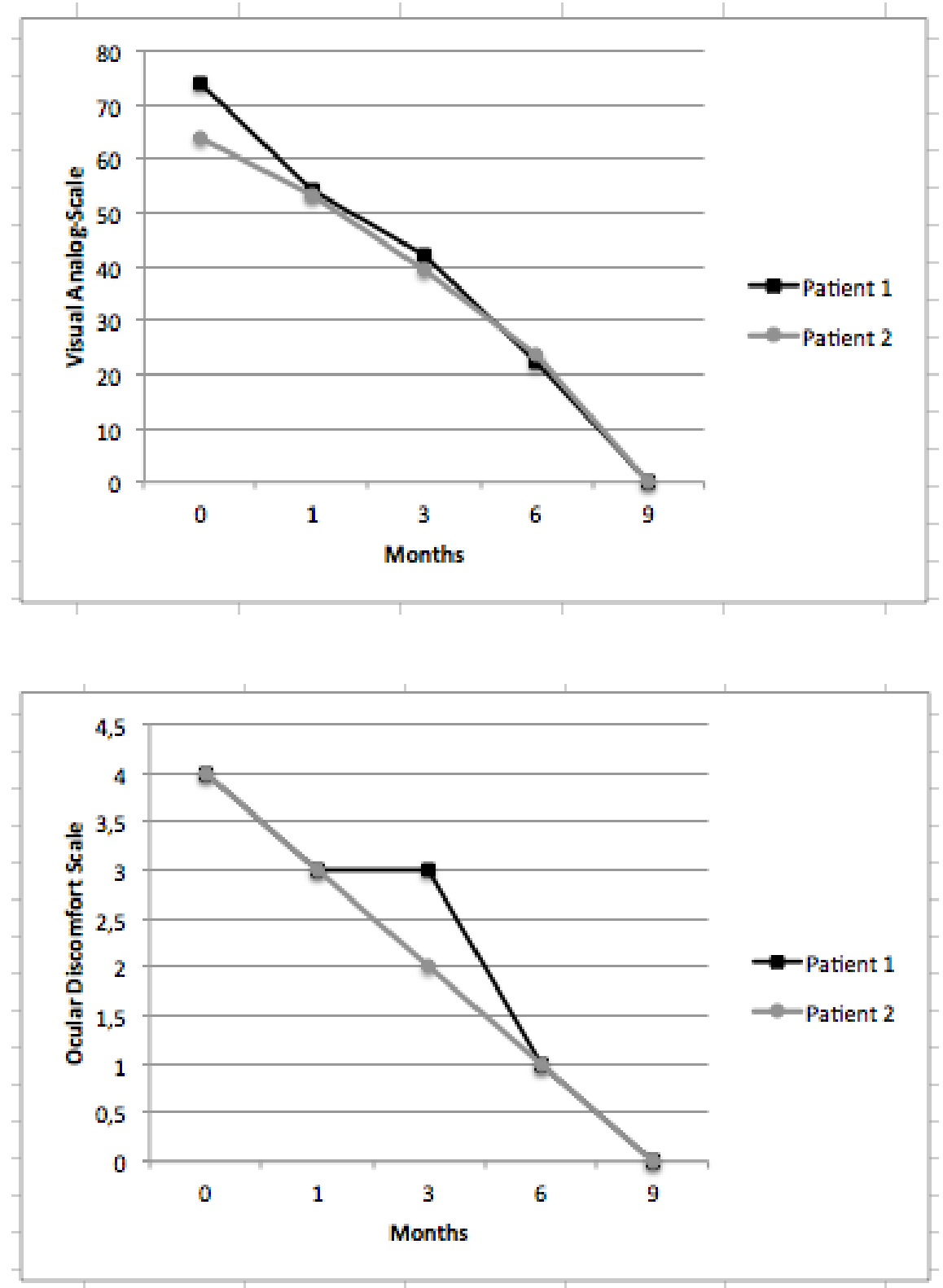

\section{Hosted file}

Table.doc available at https://authorea.com/users/340024/articles/473193-long-termefficacy-and-safety-of-omalizumab-in-conventional-treatment-resistant-vernalkeratoconjunctivitis-case-reports-and-literature-review 